\title{
An Analysis of Biological Characteristics of Macrobrachium rosenbergii (de Man) in Relation to Pond Production and Marketing in Thailand
}

\author{
C. KWEI LIN ${ }^{1,3}$ and MALI BOONYARATPALIN ${ }^{2}$ \\ ${ }^{1}$ Great Lakes Research Division, University of Michigan, Ann Arbor, MI 48109 (U.S.A.) \\ ${ }^{2}$ National Inland Fisheries Institute, Bangkhen, Bangkok (Thailand) \\ ${ }^{3}$ Present address: Agricultural and Food Engineering Division, Asian Institute of Technology, \\ P.O. Box 2754, Bangkok (Thailand) \\ Contribution No. 86-9 of CRSP/Pond Dynamics, The University of Michigan.
}

(Accepted 18 April 1988)

\section{ABSTRACT}

Lin, C.K. and Boonyaratpalin, M., 1988. An analysis of biological characteristics of Macrobrachium rosenbergii (de Man) in relation to pond production and marketing in Thailand. Aquaculture, 74: 205-215.

Data on production and marketing of giant freshwater prawn were collected over a 7-month grow-out period through collaboration with a medium-sized commercial prawn farm in central Thailand. Juvenile prawns with an average weight of $4.2 \mathrm{~g}$ were stocked at a density of 6 prawns/ $\mathrm{m}^{2}$ in three 0.5 -ha earthen ponds. Average growth rate determined during the first 3 months of the grow-out period was $0.4 \mathrm{~g} /$ prawn per day; prawns of marketable size were harvested selectively during the remaining 4 months of the rearing period, resulting in a total accumulated yield of 1.3 tonnes/ha with an average prawn weight of $32 \mathrm{~g}$ and $60 \%$ survival. As different sexes and sizes of prawns were sold at different prices, the harvests were customarily sorted into several categories: large, medium, and small males, long-clawed males, soft shells, females with eggs, females without eggs, and terminal males. The total weight and number of prawns recorded for each of these categories showed that the female to male ratios were $1.6: 1$ and $4: 1$ by weight and number, respectively while the ratio of short to long-clawed males was $3: 1$ by weight and $4: 1$ by number. Four percent of the marketable population was termed "soft shells" and $64 \%$ of the females bore eggs. The ratio of head weight to tail weight of marketable prawns varied substantially among the different categories: 1.0:1 for females, 2.5:1 for long-clawed males, and 1.6:1 for short-clawed males. Females predominated in the first and second 1.5-month harvest periods while males predominated in the final 1.5 months of the harvest. The economic yield of prawn culture was not only determined by the biomass, but also by the population structure of the various biological categories and the harvest season. 


\section{INTRODUCTION}

Commercial farming of giant freshwater prawns in Thailand has been expanding rapidly (New et al., 1982; Lin, 1988) since its introduction in the late 1960s (Ling, 1969). The production area in 1983 was recorded to be 3000 ha with an annual production of 3000 tonnes (Royal Thai Dept. Fisheries, 1985); current production is estimated to be 5000-6000 tonnes. Such rapid expansion of freshwater prawn farming in Thailand is attributed to the bio-geographical fitness of the prawn and to anthropological factors. As Macrobrachium rosenbergii is indigenous to many parts of Thailand its biological adaptation and broodstock supply for pond farming have not been a major concern. Relatively abundant surface water and the favorable climate prevailing in most parts of central Thailand make prawn culture possible throughout the year. In contrast, the climatic conditions in temperate regions limit prawn culture to a single grow-out season during the warm months, making prawn farming less productive and requiring more managerial manipulation to maximize the yield (Brody et al., 1980; Smith et al., 1981; R'anan and Cohen, 1983; Karplus et al., $1986 a, b)$. Since the prawn is a traditional item in the diet of Thai people, the domestic market has been the major outlet for pond-cultured prawns, and the seemingly insatiable consumer demand has been the driving force for prawn farm expansion.

Most prawns are marketed fresh as whole animals and priced according to different morphological categories. Unlike many foreign consumers who only eat the tail portion, in Thailand, prawns are prepared and consumed with their heads on, a desirable feature in most Thai cuisine. Consequently, large-size males, despite their relatively high heat to tail ratio, command a considerably higher price than females. However, the production of marketable male biomass is generally much lower than for females for most pond production in Thailand. This feature of female-dominated production is independent of stocking size and density (Karplus et al., 1986a,b). Based on differences in market price, the prawns are customarily sorted into several categories and priced in the following order: (1) large, (2) medium and (3) small short-claw males, (4) long-claw males, (5) females without and (6) with eggs, (7) "soft shells" (newly molted), and (8) terminal males. Terminal males are prawns that have stopped molting and whose shells appeared rough and soiled. Thus, the composition of the population is of primary importance to biomass production as well as economic yield of prawns. This labor-intensive sorting process is probably unique to Thailand. In contrast, post-harvest processing and marketing of prawn products in other countries are less sophisticated as only tails are consumed, making the product much less competitive to penaeid shrimp (Smith et al., 1980).

The current production and marketing strategies practised among Thai prawn farmers have evolved from artisanal to a relatively sophisticated pro- 
duction system. Despite the success of large-scale prawn farming in Thailand, little production and marketing information has been documented. We present here results of a detailed investigation on the population structure of various morphotypes in relation to production and marketing for a typical mediumsize farm in Thailand.

\section{MATERIAL AND METHODS}

The prawn grow-out trials were conducted for a period of 7 months from March through September 1985. Three 0.5-ha earthen ponds, belonging to a commercial prawn farm, were dried and limed with $600 \mathrm{~kg} / \mathrm{ha}$ of agricultural lime before filling the ponds with water from an irrigation canal. Wild fish were removed from the incoming water using nylon nets in the pond inlets. The water level of the ponds was maintained at $1 \mathrm{~m}$, with periodic changes at a rate of $60-70 \%$ of pond volume every $10-14$ days depending on the pond water quality. Poor water quality was indicated by green water with a visibility of less than approximately $30 \mathrm{~cm}$ and prawns congregated on the upper edges at dawn. Details on pond dynamics and water quality of the prawn culture are presented elsewhere (Lin, 1988).

Juvenile prawns, with a mean weight of $4.2 \mathrm{~g}$, were seined from nursery ponds and stocked at a density of 6 prawns $/ \mathrm{m}^{2}$. Prawns were fed twice daily (early morning and evening) with a formulated diet at $5 \%$ body weight per day during the first 3 months and 3\% thereafter. Formulated feed, made monthly at the farm, contained approximately $30 \%$ crude protein with the following ingredients ( $\%$ dry weight): fresh trash fish ( $23 \%)$, soybean meal $(23 \%)$, broken rice $(23 \%)$, rice bran $(9 \%)$, leucaena meal $(4 \%)$, shrimp shells $(4 \%)$, fish meal $(9 \%)$, calcium phosphate $(1 \%)$, vitamin and mineral premix (4\%). Prawn growth rate was determined monthly for the initial 3 months by taking cast net samples at 10 evenly-spaced locations in each pond. Standard length (eye orbit-telson) and body weight (all weights reported as wet) were measured for 100-300 prawns/pond at each sampling time. Marketable size prawns were harvested selectively by seining at approximately 1.5 -month intervals starting at the fourth month of the grow-out period. At each partial harvest, prawns below marketable size were returned to the same pond. Total harvest was made at the end of the 7-month grow-out cycle by seining, followed by hand picking after the ponds were drained. The prawns below marketable size harvested by seining were restocked into new ponds and are referred to as restocking; those picked by hand after draining the ponds are recorded as remaining. Sexes were not determined for the restocking and remaining populations, but the prawns were counted and weighed.

The crop at each harvest was sorted into the following categories: long-clawed males, short-clawed males of large (no. 1, >90 g/prawn), medium (no. 2, 70$90 \mathrm{~g} /$ prawn), and small (no. 3, 50-70 g/prawn) sizes, females with and without 
eggs, soft shells and terminal males. The total weight for each category was determined and the number of prawns was estimated based on count of a 1-2 $\mathrm{kg}$ sample. Average weight and length of whole prawn, claw, head and tail were determined by measuring 30 individual prawns of each category. The market price for each category of prawn was obtained from the farmer after prawns were sold to the dealer.

\section{RESULTS}

Data collected for total production, growth rate, and survival rate of prawns showed great similarity among the three replicate ponds (Table 1). During the 7 -month grow-out period, the average yield was $711 \mathrm{~kg} /$ pond which extrapolates to an annual yield of $2343 \mathrm{~kg} / \mathrm{ha}$. The average prawn grew from 4 to $36 \mathrm{~g}$, with an average daily weight gain of $0.4 \mathrm{~g}$ during the 3 -month preharvest period. The survival rate throughout the grow-out period was $60 \%$, or 4 juveniles/ $\mathrm{m}^{2}$.

\section{Population structure}

Table 2 shows the population structure and biomass of each category of marketable prawn as well as the number and weight of unmarketable prawns. The marketable yield comprised $77 \%$ of the entire population and $88 \%$ of the total weight. Only $19 \%$ of the marketable prawn population were males while $77 \%$ were females of which $64 \%$ bore eggs at the time of harvest. When based on weight, the marketable yield was comprised of $36 \%$ males and $59 \%$ females. The remaining percentage was made up by soft-shell prawns which were not sorted into sexes. Individual prawn weight ranged widely from $26 \mathrm{~g}$ for the smallest females without eggs in the first harvest to $130 \mathrm{~g}$ for the largest longclawed male in the final harvest (Fig. 1). The average weight of the no. 1, longclawed and soft shells was over $80 \mathrm{~g} /$ prawn; no. 2 and no. 3 males averaged 60 $80 \mathrm{~g}$ and $50-60 \mathrm{~g}$, respectively, while the females with and without eggs aver-

\section{TABLE 1}

Accumulated biomass yield (number and weight), survival rate, and weight gain of prawns in three rearing ponds during a 7 -month grow-out period

\begin{tabular}{|c|c|c|c|c|c|c|c|}
\hline \multirow[t]{2}{*}{ Pond } & \multicolumn{2}{|c|}{ Total count } & \multicolumn{2}{|c|}{ Total weight $(\mathrm{kg})$} & \multirow{2}{*}{$\begin{array}{l}\text { Survival } \\
(\%)\end{array}$} & \multicolumn{2}{|l|}{ Weight gain } \\
\hline & Stocking & Harvest & Stocking & Harvest & & Total $(\mathrm{kg})$ & Mean $(\mathrm{g})$ \\
\hline 1 & 32760 & 19826 & 130.4 & 708.8 & 60 & 578.4 & 31.7 \\
\hline 2 & 31920 & 19156 & 135.7 & 718.4 & 60 & 582.7 & 33.2 \\
\hline 3 & 33064 & 19676 & 142.5 & 706.6 & 59 & 564.1 & 31.6 \\
\hline Mean & 32581 & 19552 & 136.2 & 711.3 & 60 & 575.1 & 32.2 \\
\hline
\end{tabular}




\section{TABLE 2}

Population structure and total weight composition of marketable and undersized prawns of various categories (values are means, $x$, and standard deviations, s.d., of three rearing ponds)

\begin{tabular}{|c|c|c|c|c|c|c|c|c|}
\hline \multirow[t]{2}{*}{ Type } & \multicolumn{4}{|c|}{ Weight (kg) } & \multicolumn{4}{|c|}{ Number of prawns } \\
\hline & $x$ & s.d. & $\%$ & s.d. & $x$ & s.d. & $\%$ & s.d. \\
\hline Female+egg & 233.8 & 2.2 & 33.0 & 0.6 & 7358 & 119 & 37.6 & 0.9 \\
\hline Female-egg & 131.9 & 11.3 & 18.6 & 1.6 & 4162 & 331 & 21.3 & 1.6 \\
\hline Male no. 1 & 57.5 & 2.7 & 8.1 & 0.3 & 566 & 27 & 2.9 & 0.2 \\
\hline Male no. 2 & 81.0 & 10.1 & 11.4 & 1.4 & 1129 & 146 & 5.8 & 0.8 \\
\hline Male no. 3 & 29.1 & 7.1 & 4.1 & 1.0 & 530 & 141 & 2.7 & 0.7 \\
\hline Long claws & 51.9 & 2.3 & 7.3 & 0.3 & 562 & 28 & 2.9 & 0.2 \\
\hline Terminal males & 3.4 & 1.4 & 0.5 & 0.2 & 34 & 14 & 0.2 & 0.1 \\
\hline Soft shells & 33.4 & 3.4 & 4.7 & 0.4 & 672 & 66 & 3.5 & 0.4 \\
\hline Restocking & 70.7 & 2.7 & 10.0 & 0.4 & 3184 & 226 & 16.3 & 1.1 \\
\hline Remaining & 18.0 & 7.1 & 2.6 & 0.9 & 1354 & 477 & 6.9 & 2.3 \\
\hline Marketable & 622.5 & 12.8 & 87.5 & 1.4 & 15015 & 154 & 76.8 & 1.9 \\
\hline Unmarketable & 88.7 & 9.8 & 12.5 & 1.5 & 4538 & 432 & 23.2 & 1.9 \\
\hline Total prawns & 711.3 & 5.1 & 100.0 & 0.0 & 19553 & 287 & 100.0 & 0.0 \\
\hline
\end{tabular}

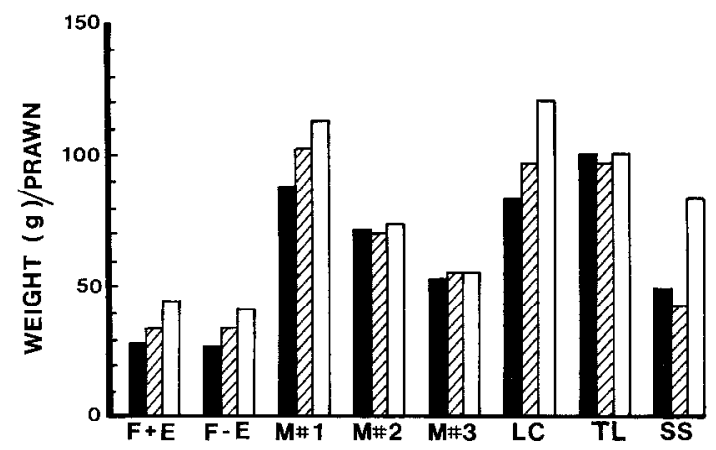

Fig. 1. Weight variation (g/prawn) among biological categories of prawns from three partial harvests. Solid bar represents the first harvest, striped the second, and blank the third; F+E, females with eggs; $F-E$, females without eggs; $M \# 1$, large males; $M \# 2$, medium males; $M \# 3$, small males; LC, long-clawed male; TL, terminal males; SS, soft-shell prawns.

aged less than $40 \mathrm{~g}$. The size of each category also varied among the three harvests, particularly the female and large male populations. In general, their sizes were smaller in the first harvest and the progression was probably the result of partial cropping which reduced population density by $35 \%$ at each of the first two harvests.

The population structure and yield of prawns among the three harvests exhibited considerable variation (Fig. 2). While the number of females com- 


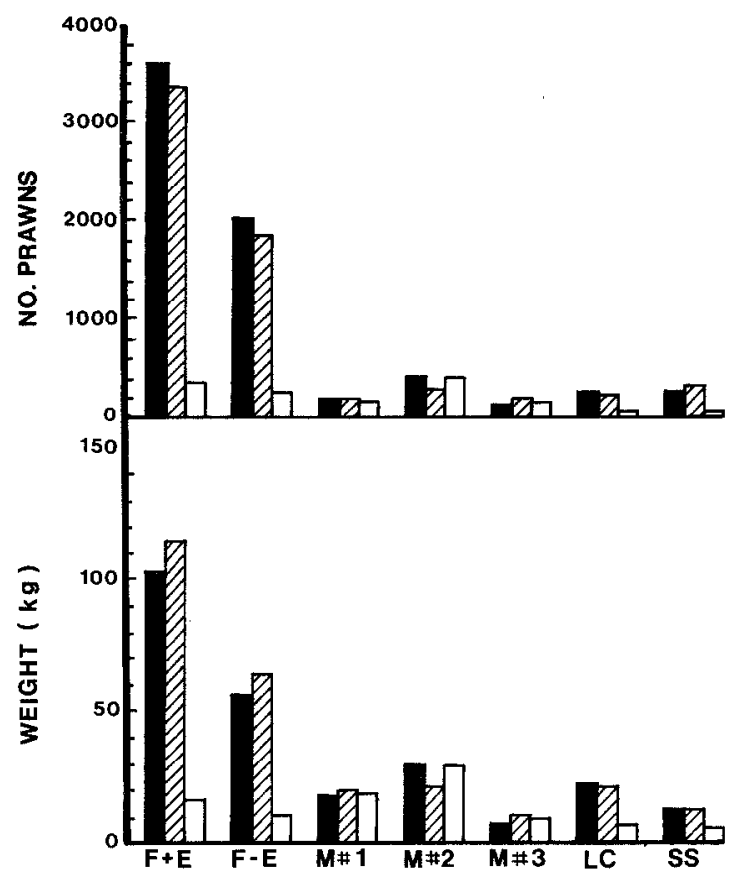

Fig. 2. Total biomass wet weight and population structure among biological categories of prawns from three partial harvests (see Fig. 1 for symbols).

prised greater than $80 \%$ in each of the first and second harvests and $43 \%$ in the third, their respective biomass in each of these three harvests was only $63 \%, 67 \%$, and $28 \%$. Over $50 \%$ of the female population bore eggs in the first and second harvests compared to only $20 \%$ in the third. Sexes were not determined for the $23 \%$ unmarketable population.

\section{Variation in body proportions}

Both length and weight proportions of claw, tail, and head varied considerably between males and females as well as between the long- and short-clawed males (Table 3). For long-clawed males, the average claw length was $130 \%$ of body length and claw weight was $23 \%$ of whole prawn weight with the tail weight being $28 \%$ of total weight. In contrast, the claw of short-clawed males measured only $84 \%$ of the body length and $10 \%$ of the total weight, while the tail was $38 \%$ of total weight. Female prawns possessed relatively small claws, measuring $62-65 \%$ of body length and $6-7 \%$ body weight, and had proportionately greater tail weight (an average of $50 \%$ ). Furthermore, the head weight for long- and short-clawed males comprised 72 and $62 \%$ of the body weights, respectively, compared to $49-52 \%$ for the females. 


\section{TABLE 3}

Proportions (\% mean \pm 1 s.d.) of claw length and weight, and head and tail weights in relation to total body length and weight, and claw weight to head weight for male and female prawns

\begin{tabular}{|c|c|c|c|c|}
\hline \multirow[t]{2}{*}{ Proportion } & \multicolumn{2}{|l|}{ Male } & \multicolumn{2}{|l|}{ Female } \\
\hline & Long-claw & Short-claw & With eggs & Without eggs \\
\hline$\frac{\text { Claw length }}{\text { Total length }}$ & $130 \pm 10$ & $84 \pm 14$ & $62 \pm 5$ & $65 \pm 9$ \\
\hline$\frac{\text { Claw weight }}{\text { Total weight }}$ & $23 \pm 5$ & $10 \pm 3$ & $7 \pm 2$ & $6 \pm 2$ \\
\hline$\frac{\text { Claw weight }}{\text { Head weight }}$ & $32 \pm 6$ & $14 \pm 4$ & $13 \pm 4$ & $13 \pm 5$ \\
\hline$\frac{\text { Head weight }}{\text { Total weight }}$ & $72 \pm 3$ & $62 \pm 2$ & $52 \pm 1$ & $49 \pm 1$ \\
\hline$\frac{\text { Tail weight }}{\text { Total weight }}$ & $28 \pm 3$ & $38 \pm 2$ & $47 \pm 2$ & $51 \pm 2$ \\
\hline
\end{tabular}

\section{TABLE 4}

Variation in market price (US\$ $\$ \mathrm{~kg}$ ) for different prawn categories in three partial harvests at different times of the year

\begin{tabular}{llll}
\hline Type & 6 June 1985 & 28 July 1985 & 27 Sept. 1985 \\
\hline Female + egg & 2.1 & 2.6 & 3.3 \\
Female-egg & 2.4 & 2.9 & 4.3 \\
Male no. 1 & 4.7 & 5.6 & 6.7 \\
Male no. 2 & 4.3 & 5.0 & 6.5 \\
Male no. 3 & 3.5 & 4.3 & 5.3 \\
Long claws & 2.7 & 3.7 & 5.1 \\
Terminal males & 1.2 & 1.2 & 1.4 \\
Soft shells & 2.5 & 3.1 & 3.5 \\
\hline
\end{tabular}

\section{Marketing}

As the price of prawns differed with prawn size and form, as well as season of harvest, the economic yield for pond culture was not a linear relationship with the harvestable biomass (Table 4 ). The overall price was lower in June and higher during the latter part of the year. Large males (no. 1, >80 g/prawn) with short claws commanded the highest price at US\$4.7-6.7/kg and terminal males the lowest price at US $\$ 1.2-1.4 / \mathrm{kg}$. Despite their large average sizes, the long-clawed males and soft shells were sold at a price comparable with the smaller females at US $\$ 2.5-5.0 / \mathrm{kg}$. Females with eggs were less desirable than those without. Fig. 3 shows the income derived from various prawn categories in each of the three harvests. During the first and second harvests, the income 


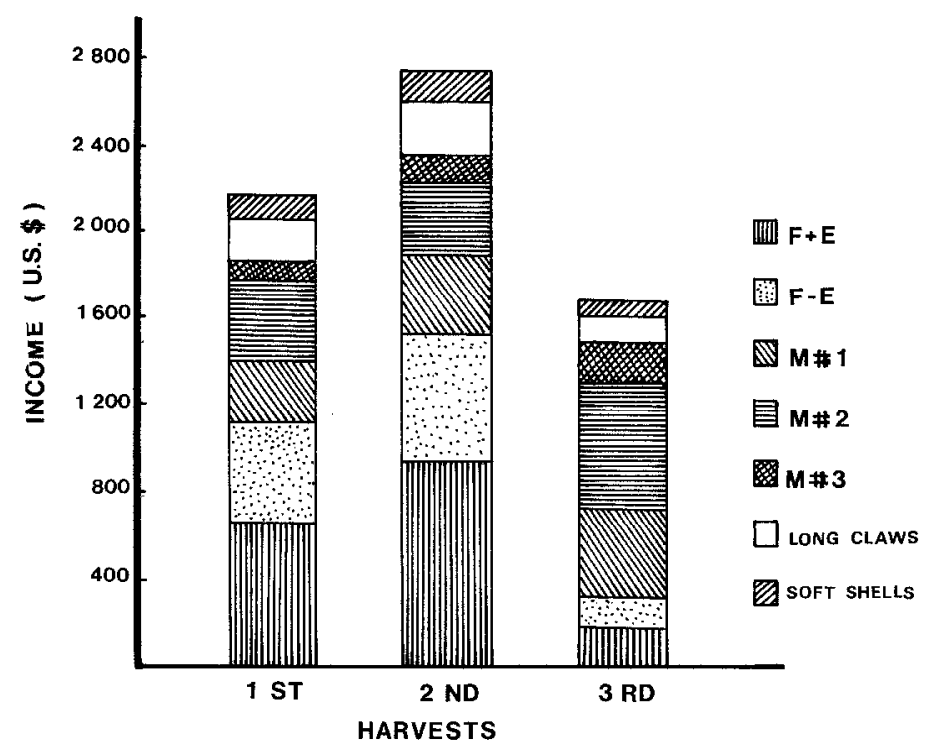

Fig. 3. Comparison of income composition from a one-ha yield by biological categories for prawns from three harvests (see Fig. 1 for symbols).

from the female crop accounted for approximately $50 \%$ of each harvest while the female biomass was greater than $60 \%$. However, by the third harvest, economic yield from females was only $20 \%$ since the biomass had dropped to $28 \%$ of the total yield, while the income from males increased to $70 \%$ and the yield equaled $65 \%$ of the biomass. The price increase coupled with the proportionately higher production of male biomass improved the income from the third harvest.

\section{DISCUSSION}

Detailed analyses on production and marketing of pond-reared freshwater prawns in Thailand clearly showed that the economic income is not only related to the total yield but also depends on the structure of the population in terms of such features as sex ratio, male size differential, and claw types. The present data indicated that the total marketable population was dominated by females (male:female $=0.25$ ). Smith et al. (1981) also found that significantly more females occurred in all experimental ponds stocked with a mixture of postlarvae and juveniles or with juveniles only. The occurrence of greater female abundance has been observed not only under various stocking densities (Karplus et al., 1986a), but also with various size-graded juveniles (Karplus et al., 1986b). The numerical female dominance in the marketable lots might be explained by the common fact that females grew more evenly in size and reached marketable size in greater percentages, while males are polarized into 
large and small (petit) populations. Brody et al. (1980) observed that the unmarketable petit males constituted as much as $50 \%$ of the male population. In our case, it was probable that the majority of the unmarketable population $(23 \%)$ were petit males. Unfortunately, the sexing of restocked and remaining populations was not carried out because their small body size obscured the external sex features, making accurate sexing difficult. From the processing viewpoint, a dominant yield of females would be advantageous if the market demand was only for the tail portion of the product since the average tail weight was approximately $50 \%$ of the total female body weight compared to $38 \%$ for average short-claw males. However, this is not the case in Thailand, where most of the prawns are marketed domestically and consumed whole. Generally, the price increases with larger prawn sizes, thereby making males more valuable. Thus, it would be desirable to increase the male constituent of the population in grow-out ponds.

The practice of intermediate, partial harvest in Thailand is definitely a sound management strategy for two reasons. One, the females that dominated the population and matured relatively early at a small size $(30-40 \mathrm{~g})$ could be selectively removed in the early harvest. The current data show that females comprised $63 \%$ of the total marketable biomass in the first harvest after 4 months of grow-out, and $65 \%$ of those females bore eggs. In fact, harvesting females prior to their gravid stage would be advantageous because the eggless females command a better price. Under the current culture practice, the ponds were started with a density considered to be optimal ( 6 prawns $\left./ \mathrm{m}^{2}\right)$, but each partial harvest substantially reduced population density in the ponds. Continuous restocking with postlarvae or juveniles to sustain the density was not practised for the reason that the competition between the newly stocked cohorts and original residents might in fact adversely affect production. Malecha (1986) reported that competition between the two cohorts significantly lowered production. The second reason is that intermediate harvestings also removed the large males and allowed the production to shift gradually to males which commanded a comparatively greater price.

The processing yield of the prawn product varies considerably with claw type and sex and one of the most disadvantageous features in freshwater prawn marketing is the product's low processing yield (tail meat) which ranged from $28 \%$ for the long-claw males to $51 \%$ for the eggless females. Apparently, the proportion of tail yield decreases with increasing prawn size and females offer significantly greater yield than males of all sizes (Smith et al., 1980). In comparison, tail yield of penaeid shrimp, on average, comprises greater than $60 \%$ of the whole body with little variation between sexes (National Marine Fisheries Service, 1978).

The existence of short- and long-clawed male populations has long been recognized and is of concern to both farmers and biologists alike. To farmers and consumers, long-clawed males, through large in body weight (80-130 g/ 
prawn), are less desirable because of the greater proportion of claw waste, ranging from 18 to $28 \%$ of prawn weight compared to $7-13 \%$ for the shortclawed males. Although the long-claw population in the current study comprised less than $10 \%$ of the total marketable population, their aggressive sexual and territorial behavior may exhibit a much greater influence on production than their numerical minority status would indicate. In practice, the long-claw males were fast growers and most of them were removed during the earlier partial harvests. In contrast, the orange short-clawed variety was reported to be of superior quality because of its proportionately greater tail weight and more docile nature (Sandifer and Smith, 1977). Therefore, increasing the proportion of short-claw males, either through broodstock manipulation or managerial strategies as those proposed by Malecha (1986), would be a viable means of augmenting biomass and economic yield of prawn farming in Thailand or elsewhere in the world.

\section{ACKNOWLEDGEMENTS}

This work was financially sponsored by three agencies: Collaborative Research Support Program (CRSP/Pond Dynamics) funded by United States Agency for International Development (Grant No. DAN-4023-G-S5-2074-00), Network of Aquaculture Centers for Asia, and National Inland Fisheries Institute of the Thai Department of Fisheries. Mr. S. Amnuey and his family provided the pond facility and logistic support and deserve our greatest appreciation.

\section{REFERENCES}

Brody, T., Cohen, D., Barnes, A. and Spector, A., 1980. Yield characteristics of the prawn Macrobrachium rosenhergii in temperate zone aquaculture. Aquaculture, 21: 375-385.

Karplus, I., Hulata, G., Wolfarth, G.W. and Halevy, A., 1986a. The effect of density of Macrobrachium rosenbergii raised in earthen ponds on their population structure and weight distribution. Aquaculture, 52: 307-320.

Karplus, I., Hulata, G., Wolfarth, G.W. and Halevy, A., 1986b. The effect of size-grading juvenile Macrobrachium rosenbergii prior to stocking on their population structure and production in polyculture. I. Dividing the population into two fractions. Aquaculture, 56: 257-270.

Lin, C.K., 1988. Production and consumption of freshwater prawns - the Thai way. Abstract of paper presented at the World Aquaculture Society Conference, Honolulu, HI.

Ling, S.W., 1969. Methods of rearing and culturing Macrobrachium rosenbergii. FAO Fish. Rep., 3: 607-619.

Malecha, S.R., 1986. New techniques for the assessment and optional management of growth and standing crop variation in the cultured freshwater prawn, Macrobrachium rosenbergii. Aquacult. Eng., 5: 183-197.

National Marine Fisheries Service, 1978. Fisheries statistics of the United States 1975. Statistical Digest No. 69, U.S. Government Printing Office, Washington, DC. 
New, M., Singholka, B.S. and Vorasayan, P., 1982. Current status of freshwater prawn farming in Thailand. In: M.B. New (Editor), Giant Prawn Farming. Elsevier, Amsterdam, pp. 333-349.

Ra'anan, Z. and Cohen, D., 1983. Production of the freshwater prawn Macrobrachium rosenbergii in Israel. II. Selective stocking of size sub-populations. Aquaculture, 31: 369-379.

Royal Thai Department of Fisheries, 1985. Fisheries record of Thailand 1983. Fisheries Statistics Subdivision and Fisheries Policy and Planning Division, Department of Fisheries, Ministry of Agriculture and Cooperatives, Bangkok, Thailand, $139 \mathrm{pp}$.

Sandifer, P.A. and Smith, T.I.J., 1977. Preliminary abservations on a short claw growth form of the Malaysian prawn, Macrobrachium rosenbergii (de Man). Proc. Natl. Shellfish. Assoc., 67: 123-124 (abstr.).

Smith, T.I.J., Waltz, W. and Sandifer, P.A., 1980. Processing yields for Malaysian prawns and the implications. Proc. World Maricult. Soc., 11: 557-569.

Smith, T.I.J., Sandifer, P.A., Jenkins, W.C. and Stokes, A.D., 1981. Effect of population structure and density at stocking on production and commercial feasibility of prawn (Macrobrachium rosenbergii) in temperate climates. J. World Maricult. Soc., 1: 233-250. 